\title{
High Efficient Bidirectional Battery Converter for Residential PV Systems
}

\author{
Cam Pham \\ Department of Energy Technology \\ Aalborg University \\ Aalborg, Denmark \\ cpham05@student.aau.dk
}

\author{
Tamas Kerekes \\ Department of Energy Technology \\ Aalborg University \\ Aalborg, Denmark \\ tak@et.aau.dk
}

\author{
Remus Teodorescu \\ Department of Energy Technology \\ Aalborg University \\ Aalborg, Denmark \\ ret@et.aau.dk
}

\begin{abstract}
Photovoltaic (PV) installation is suited for the residential environment and the generation pattern follows the distribution of residential power consumption in daylight hours. In the cases of unbalance between generation and demand, the Smart PV with its battery storage can absorb or inject the power to balance it. High efficient bidirectional converter for the battery storage is required due high system cost and because the power is processed twice. A $1.5 \mathrm{~kW}$ prototype is designed and built with CoolMOS and $\mathrm{SiC}$ diodes, $>95 \%$ efficiency has been obtained with $200 \mathrm{kHz}$ hard switching.
\end{abstract}

Keywords - Split converter, Dual phase converter, bidirectional DC-DC converter, Smart PV converter, Battery converter, SiC, CoolMOS.

\section{INTRODUCTION}

To prevent the climate change caused by the human activities, worldwide governments work on a common goal to reduce carbon dioxide emission. The Danish energy policy in year 2025 for power system is to have 50 percent of power production to be generated from renewable sources and to be independent of fossil fuels in year 2050 [1].

Compared to wind power, PV installation is more accepted in residential area and the generation follows the residential power consumption pattern during daylight hours. In cases of unbalance between generation and demand, the Smart PV with its battery can absorb or inject the power to balance it. Beside functionalities of an inverter with storage, the Smart PV can support with reactive power and communicate with the grid. Together they make Smart PV an essential component of grid infra structure.

Sol-ion project took place between March 2008 and December 2011 and in this project industries and research institutes from France and Germany collaborated to develop an innovative and competitive PV energy system. The energy management system (EMS) of the Sol-ion project for selfconsumption is depicted in Fig.1, where the batteries will be discharged when there is no or insufficient generation from the PV. In case of surplus generation, the energy is stored in batteries and feed in when the batteries is charged [2].

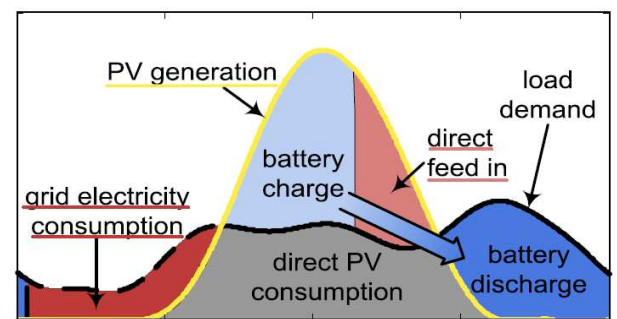

Fig.1 The EMS from Sol-ion project [2]

Back in 2009, the average unit price of electricity for residential householders in Denmark was nearly $0.236 € / \mathrm{kWh}$, but only $25 \%$ of the price is the electric energy [3]. In the long term, self generation is an economic benefit and with storage capability, the benefit can be maximised by trading electricity with Spot Price from Nordpool. The stored energy can either be supplied or sell to the grid, when the spot price swings up.

The Sol-ion self-consumption system is illustrated in Fig. 2, where PV and battery are boosted to a common DC link voltage and an inverter is used for grid connection.

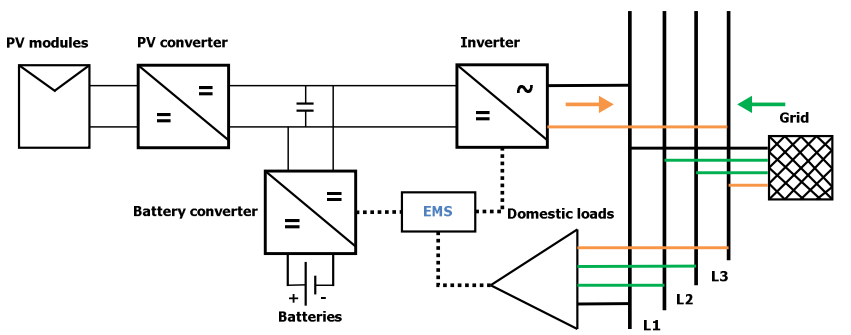

Fig. 2 An overview of the Sol-ion system

For three phase systems, $700 \mathrm{~V}$ DC link is required to generate 400Vac. A high efficient bidirectional DC-DC converter for battery storage is needed to reduce the payback time, because the energy price from PV generation is high due to the system cost and the energy is processed twice; charge and discharge.

\section{TOPOLOGIES}

Numerous references have been reported about bidirectional DC-DC converter. Basically it can be divided 
into two groups; isolated and non-isolated [4]-[7]. The characteristic of battery converter is the bidirectional of current flow.

\section{A. Boost-Buck converter (BBC)}

For non-isolated applications, the converter can be realised with MOSFET as shown in Fig. 3, where a boost converter can be seen from right to left and see from left to right, a buck converter can be identified. By using MOSFET, this bidirectional converter can be realised with very few components, as the intrinsic diode and switch are in one component and the boost inductor is the output filter in buck mode. Furthermore MOSFETs can switch with very high frequency, thus reduces the size of magnetic and filter components and consequence, the cost and volume of the converter are reduced. From the performance point of view, anti-parallel of the diode and the switch makes active freewheeling and rectify possible and these improve the efficiency. The drawbacks of this converter in $700 \mathrm{~V}$ application are followed by using higher voltage switches; $1200 \mathrm{~V}$.

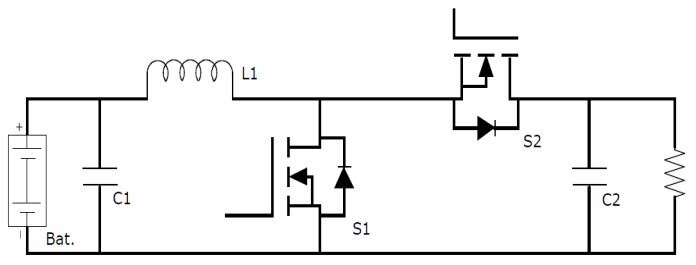

Fig.3 Boost-buck converter (BBC) realised with MOSFETs.

\section{B. Split Boost-Buck converter (SBBC)}

To overcome the drawbacks from higher voltage switches, the $700 \mathrm{~V}$ DC link can be obtained, by taking the differential of $\pm 350 \mathrm{~V}$ legs as illustrated in Fig.4. This allows utilisation of lower voltage switches; $600 \mathrm{~V}$ and inherit the advantages of lower conduction and switching losses. The drawbacks from this topology are followed by the increased number of components.

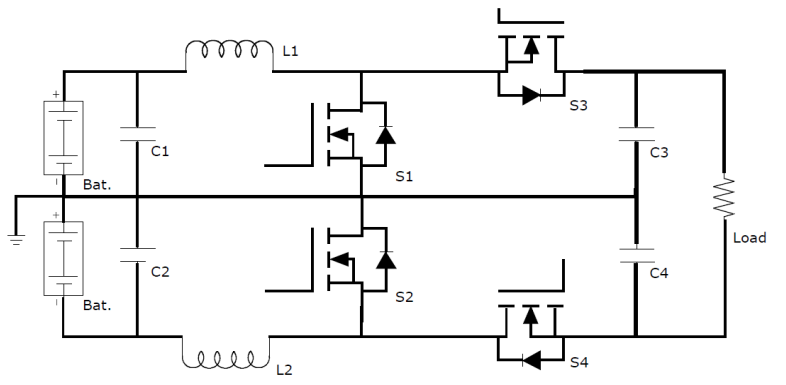

Fig.4 Split Boost-Buck converter (SBBC)

\section{Interleaved Dual-Phase Split Boost-Buck converter (IDPSBBC)}

To increase the efficiency, the conduction losses can be reduced by dividing the process power into multiple phases. The converter in Fig. 5 shows a dual-phase SBBC. The advantages for multiple phases are: one of the phases can be shut down in light load to improve the efficiency and with interleaved switching, input and output current ripple can be reduced. This reduces electrical stress on the battery and output capacitor, respectively [8]-[10].

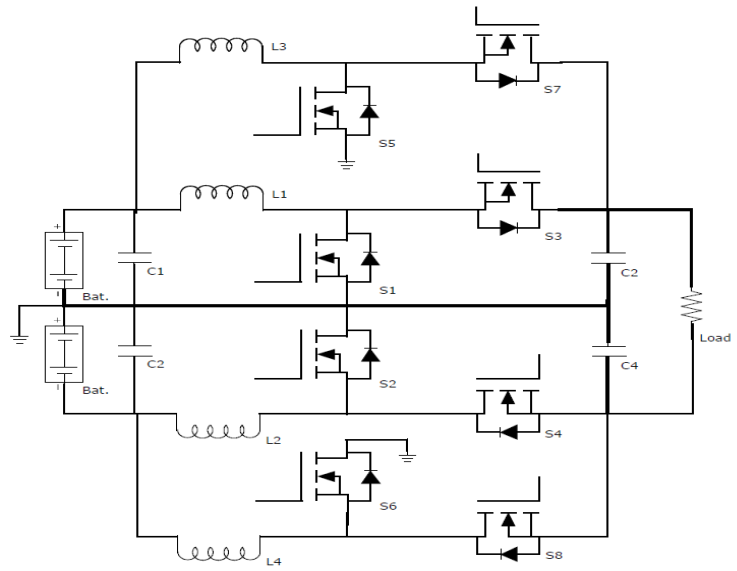

Fig.5 Interleaved Dual-Phase Split Boost-Buck converter (IDPSBBC )

To recap, three different non-isolated bidirectional DC-DC converters have been presented for interface with battery; the characteristic of them are: $\mathrm{BBC}$ is with very few components, SBBC can use lower voltage switches and IDPSBBC are the use of lower voltage switches and reduce conduction losses by distribute the energy into multiple phases.

\section{METHODOLOGY}

The main sources of power losses in the converter are inductors and semiconductors. In continuous-current conduction mode (CCM) with small current ripple, losses in inductor is governed by its winding loss, which can be expressed as (1).

$$
P_{\text {inductor, winding }}=E S R_{L} \cdot I_{L}^{2}
$$

In the MOSFETs, the conduction losses (2) are governed by the on-resistance and the switching losses are determined by the dynamic specifications during switch-on (3) and switch-off (4). Compare to a transistor without reverse recovery, the reverse recovery of the body diode is an add-on to the loss and the switch-on time. The conduction loss of the body diode can be computed as (5) and the switching loss of the diode is dominated by the switch-on loss (6) [11].

$$
\begin{aligned}
& P_{\text {conduction,MOSFET }}=R_{D S, O n} \cdot I_{D, \text { on }}^{2} \\
& P_{\text {on,MOSFET }}=\left(V_{D D} \cdot I_{D, \text { on }} \cdot \frac{t_{r i}+t_{f u}}{2}+Q_{r r} \cdot V_{D D}\right) \cdot f_{\text {switching }} \\
& P_{o f f, M O S F E T}=V_{D D} \cdot I_{D, o f f} \cdot \frac{t_{r u}+t_{f i}}{2} \cdot f_{\text {switching }} \\
& P_{\text {conduction,Diode }}=V_{F, 0 A} \cdot I_{F, \text { average }}+R_{D y n a m i c} \cdot I_{F, \text { rms }}^{2} \\
& P_{\text {switching,Diode }} \approx \frac{1}{4} \cdot Q_{r r} \cdot V_{r r} \cdot f_{\text {switching }}
\end{aligned}
$$


Where in (1)-(6): $E S R_{L}$ is the equivalent series resistance (ESR) of the inductor, $I_{L}$ is the process current of the inductor, $R_{D S \text {, on }}$ is the on-resistance of the MOSFET, $I_{D, O N}$ is the oncurrent through the MOSFET, $V_{D D}$ is the DC link voltage, $t_{r i}$ is the current rise time, $t_{f u}$ is the voltage fall time, $Q_{r r}$ is the reverse recovery charge, $t_{r u}$ is the voltage rise time, $t_{f i}$ is the current fall time, $V_{F, O A}$ is the forward voltage of the diode at zero current, $I_{F, \text { average }}$ is the average forward current of the diode, $R_{\text {Dynamic }}$ is the dynamic resistance of the diode, $I_{F, r m s}$ is the rms forward current of the diode and $V_{r r}$ is the voltage across the diode during reverse recovery.

\section{SWITCHES TECHNOLOGY}

Wide bandgap materials like SiC offer lower on-resistance, higher break down voltage and lower capacitances compared to $\mathrm{Si}$. These advantages improve the conduction as well the switching characteristics. For diodes, $\mathrm{SiC}$ has almost completely removed the reverse recovery charge, the reverse recovery time is reduced to tens of nano second, which extends the frequency of hard switching. SiC MOSFET is relative new in the commercial marked and the availability is still very limited. In $600 \mathrm{~V}$ level, the revolutionary of Super junction (SJ) CoolMOS, based on $\mathrm{Si}$ material, offers competitive performance characteristics, compare to SiC MOSFET, but the dynamics of the body diode in CoolMOS suffers from high amount of reverse recovery charge. To prevent conduction of the body diode, external $\mathrm{SiC}$ diodes have connected as shown in Fig. 6 to demonstrate the advantages of SJ transistor and SiC diodes.

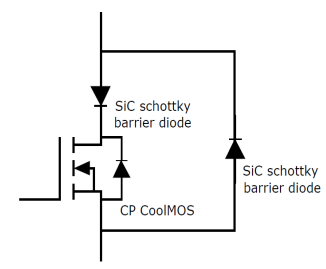

Fig.6 Modified CoolMOS to prevent conduction of body diode.

Tab.I compares the characteristics of three type of switches, which can be used in the earlier mentioned converters; a SiC MOSFET, a CoolMOS with integration of the fast body diode (CFD2) and a modified CoolMOS. Compare with the CFD2 device, the $\mathrm{SiC}$ diode reduces more than $95 \%$ of the reverse recovery charge and more than $87 \%$ of recovery time and compare with the SiC MOSFET, they are reduced more than $62 \%$ and $86 \%$, respectively. The fast switching characteristics of $\mathrm{SiC}$ do not only reduce the switching loss, but also shorter the switching transient time. Together with the advantage of low conduction and fast switching characteristics of SJ transistor, these lower the losses and extend the frequency limit of hard switching.

TAB.I COMPARISION OF SIC MOSFET WITH LATEST SJ COOLMOS AND COOLMOS WITH SIC DIODES.

\begin{tabular}{|l|c|c|c|}
\hline Characteristic & $\begin{array}{c}\text { CMF10120D } \\
\text { SiC }\end{array}$ & $\begin{array}{c}\text { IPW65R110CFD } \\
\text { CFD2 }\end{array}$ & $\begin{array}{c}\text { IPW06R099CP } \\
\text { + SCS120AG }\end{array}$ \\
\hline $\mathrm{V}_{\mathrm{DS}}$ & $1200 \mathrm{~V}$ & $650 \mathrm{~V}$ & $600 \mathrm{~V}$ \\
\hline
\end{tabular}

\begin{tabular}{|l|c|c|c|}
\hline $\mathrm{R}_{\mathrm{DS}, \text { on }}$ & $220 \mathrm{~m} \Omega$ & $110 \mathrm{~m} \Omega$ & $110 \mathrm{~m} \Omega$ \\
\hline $\mathrm{Q}_{\mathrm{g}}$ & $47 \mathrm{nC}$ & $118 \mathrm{nC}$ & $60 \mathrm{nC}$ \\
\hline $\mathrm{t}_{\mathrm{d}(\mathrm{on})}$ & $7 \mathrm{~ns}$ & $16 \mathrm{~ns}$ & $10 \mathrm{~ns}$ \\
\hline $\mathrm{t}_{\mathrm{r}}$ & $14 \mathrm{~ns}$ & $11 \mathrm{~ns}$ & $5 \mathrm{~ns}$ \\
\hline $\mathrm{t}_{\mathrm{d}(\text { off })}$ & $46 \mathrm{~ns}$ & $68 \mathrm{~ns}$ & $60 \mathrm{~ns}$ \\
\hline $\mathrm{t}_{\mathrm{f}}$ & $37 \mathrm{~ns}$ & $6 \mathrm{~ns}$ & $5 \mathrm{~ns}$ \\
\hline $\mathrm{V}_{\mathrm{F}, \text { diode }}$ & $3.5 \mathrm{~V}$ & $0.9 \mathrm{~V}$ & $1.5 \mathrm{~V}$ \\
\hline $\mathrm{t}_{\mathrm{rr}}$ & $138 \mathrm{~ns}$ & $150 \mathrm{~ns}$ & $19 \mathrm{~ns}$ \\
\hline $\mathrm{Q}_{\mathrm{rr}}$ & $94 \mathrm{nC}$ & $800 \mathrm{nC}$ & $35 \mathrm{nC}$ \\
\hline
\end{tabular}

\section{DESIGN AND EXPERIMENTATION}

\section{A. Case study}

A case study of a $3 \mathrm{~kW}$ converter is analysed; assume that the $\mathrm{BBC}$ is realised with $\mathrm{SiC}$ switches and both SBBC and IDPSBBC are realised with the modified CoolMOS. The switching frequency is decided by the inductor design, for IDPSBBC switch with $200 \mathrm{kHz}$. An inductance of $602 \mu \mathrm{H}$ is required to handle $750 \mathrm{~W}$ and can operate in CCM down to $10 \%$ of the nominal load. For the required inductance on an ETD34 cores, 85 turns are needed. With litz wire of type $32 \times 0.1 \mathrm{~mm}$ as winding, the $\mathrm{ESR}_{\mathrm{L}}$ is $0.345 \Omega$. Assume the inductance and $\mathrm{ESR}_{\mathrm{L}}$ can be doubled and the switching frequency can be the halve for BBC and SBBC, the losses can be calculated by using Eq.(1)-(6). The data can be found in datasheets [12]-[15] and the application note [16]. The analytic calculation of losses at nominal power is presented in Tab.II for worst case operation mode; boost mode.

TAB.2 POWER LOSSES OF BBC, BSC AND IDPBSC IN BOOST MODE.

\begin{tabular}{|l|c|c|c|c|}
\hline $\begin{array}{c}\text { Converter } \\
\text { type }\end{array}$ & $\begin{array}{c}\text { Plosses, } \\
\text { MOSFETs } \\
{[\mathbf{W}]}\end{array}$ & $\begin{array}{c}\text { Plosses, } \\
\text { Diodes } \\
{[\mathbf{W}]}\end{array}$ & $\begin{array}{c}\text { Plosses, } \\
\text { inductor(s) } \\
{[\mathbf{W}]}\end{array}$ & $\begin{array}{c}\text { Efficiency } \\
{[\%]}\end{array}$ \\
\hline BBC & 35 & 19.2 & 47.5 & 96.6 \\
\hline SBBC & $2 \cdot 19.3=38.6$ & $2 \cdot 3.8=7.6$ & $2 \cdot 47.5=95$ & 95.3 \\
\hline IDPSBBC & $4 \cdot 13.6=54.4$ & $8 \cdot 2.4=19.2$ & $4 \cdot 5.94=23.8$ & 96.8 \\
\hline
\end{tabular}

\section{B. Design specifications}

From Tab.II IDPSBBC shows the highest efficiency. Since the $\pm 350 \mathrm{~V}$ legs only differ from polarity, a prototype of the positive $350 \mathrm{~V}$ leg is designed and built to demonstrate the high efficiency and advantages of $\mathrm{SJ}$ transistor and $\mathrm{SiC}$ diode. The specifications of the leg are listed in Tab.III and the components in Tab.IV.

TAB. III DESIGN SPECIFICATIONS OF THE IDPSBBC LEG

\begin{tabular}{|l|l|}
\hline Output Power & Pout $=1.5 \mathrm{~kW}$ \\
\hline Input voltage window & Vin $=168-225 \mathrm{~V}$ \\
\hline Output voltage & Vout $=350 \mathrm{~V}$ \\
\hline Switching frequency & fswitching $=200 \mathrm{kHz}$ \\
\hline Theoretic efficiency & $\eta=0.968$ \\
\hline
\end{tabular}


TAB. IV MAIN COMPONENTS IN IDPSBBC LEG

\begin{tabular}{|l|l|}
\hline & $\begin{array}{l}\mathrm{L}=608 \mu \mathrm{H} \\
\text { ETD 34 core with N87 material } \\
\mathrm{N}=85 \text { turns of 32 x 0.1mm litz wire } \\
\text { Anductor L1 and L3 }\end{array}$ \\
\hline Capacitor C1 and C3 $2 \mathrm{~mm}$
\end{tabular}

The built prototype is shown in Fig. 7. It has current and voltage sensing in battery side and DC link for closed loop regulation.

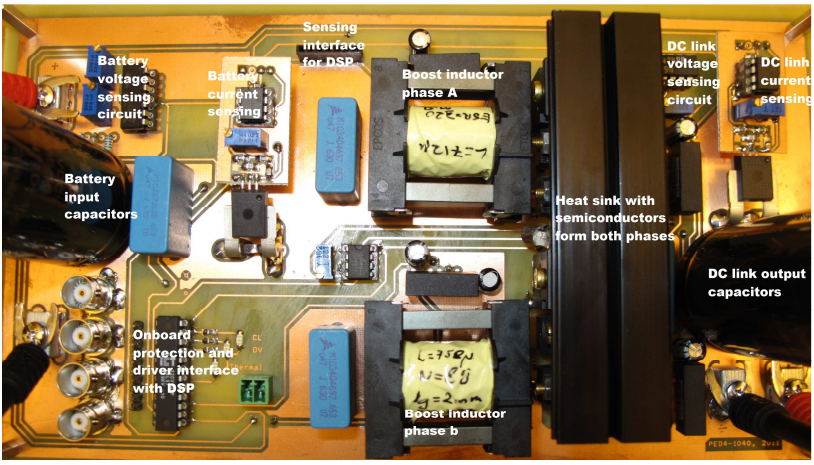

Fig. 7 The built prototype leg of IDPSBBC.

\section{Experimential results}

The prototype is tested in boost mode, where the losses are expected to be highest. The test setup is shown in Fig. 8 and the test conditions are listed in Tab.V.

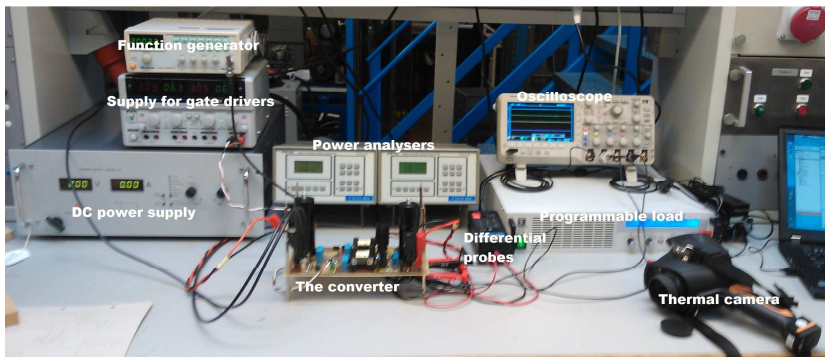

Fig. 8 The test setup.

TAB.V TEST CONDITIONS OF THE PROTOTYPE

\begin{tabular}{|l|l|}
\hline Output Power range & Pout $=0.3-1.5 \mathrm{~kW}$ \\
\hline Input voltage window & Vin $=175-192 \mathrm{~V}$ \\
\hline Output voltage & Vout $=350 \mathrm{~V}$ \\
\hline Switching frequency & fswitching $=200 \mathrm{kHz}$ \\
\hline Control & Open loop, no active freewheeling or rectify \\
\hline
\end{tabular}

Fig.9 shows the recorded signals from the scope at nominal power; channel 2 and 4 are gate signals measured normal probes and channel 1 and 3 are the drain voltages measured with differential probes. Voltage rise time is $46 \mathrm{~ns}$ and fall time is $71 \mathrm{~ns}$.

To demonstrates the thermal limit of the inductor design, the phases are heavy uneven loaded and the thermal picture is captured and shown in Fig. 10.

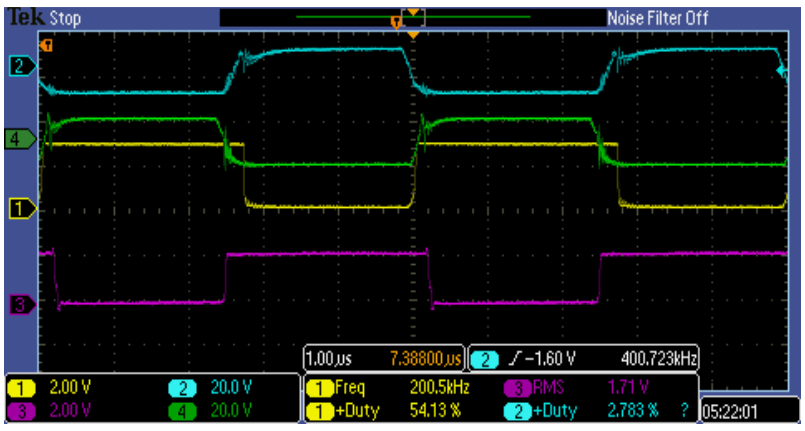

Fig.9 Gate signals and drain-source voltages of the positive leg.

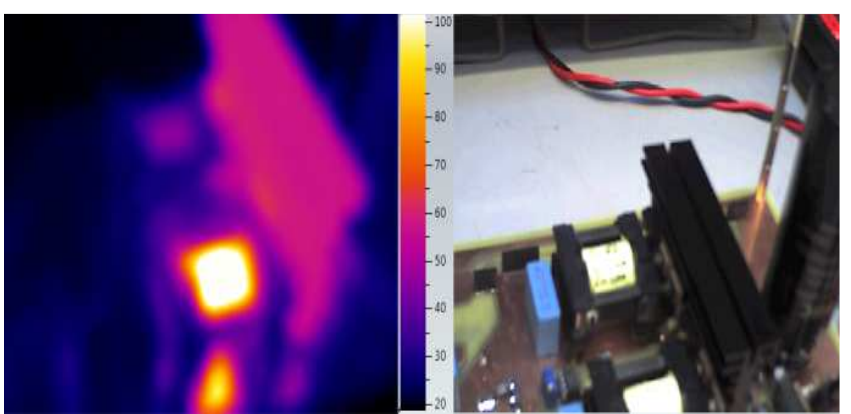

Fig.10 Thermal image of the converter during thermal test of the inductors.

The efficiency of the converter in boost mode where both phases are equally loaded is plot in Fig. 11. The efficiency at nominal load is around $95.2 \%$.

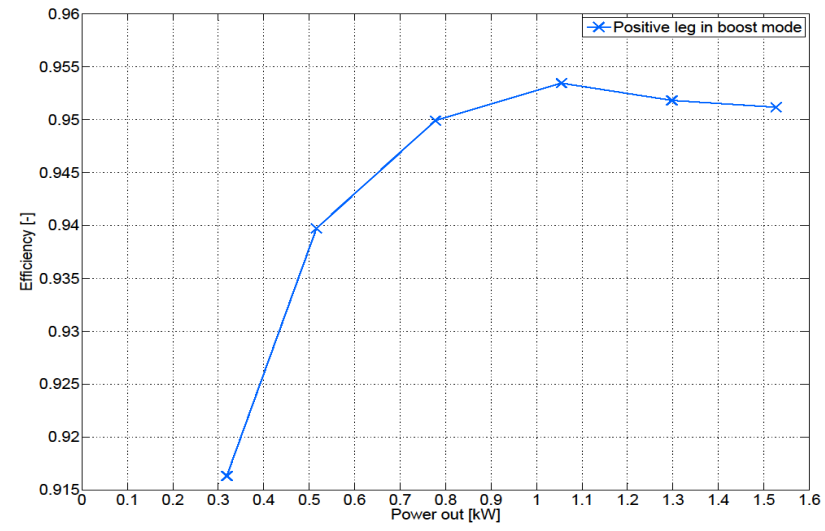

Fig.11 The efficiency plot of the positive leg in boost mode. 


\section{CONCLUSION}

In this paper three high efficient bidirectional DC-DC converters have been presented. Characteristic of the BBC topology is very few components, SBBC and IDPSBBC can use $600 \mathrm{~V}$ switches to generate $700 \mathrm{~V}$ DC link. The positive leg of IPDSBBC is built with $\mathrm{SJ}$ transistors and $\mathrm{SiC}$ diodes to demonstrate the fast switching characteristics. The prototype hard switching with $200 \mathrm{kHz}$ and is designed to operate in CCM to reduce the size of the magnetic and filter component. Rise time of $46 \mathrm{~ns}$ and fall time of 71ns confirm the superior switching characteristics. The efficiency of the prototype is around $95.2 \%$ in boost mode at $1.5 \mathrm{~kW}$.

\section{REFERENCES}

[1] Jørgen S. Christensen. "Future Perspectives - toward 2025 and 2050", Future Power Systems in Denmark, Course materials, http://www.energyminds.dk/Tema/Valgfagskursus.aspx

[2] Sol-ion project. http://www.saftbatteries.de/pdf/Intersolar_Solion_Presentation.pdf.

[3] Dansk energy. Elforsyningens tariffer \& elpriser pr. 1. januar 2009 ISSN 0909-0762.

[4] Hirose, Toshiro; Matsuo, Hirofumi; , "A consideration of bidirectional superposed dual active bridge dc-dc converter," Power Electronics for Distributed Generation Systems (PEDG), 2010 2nd IEEE International Symposium on , vol., no., pp.39-46, 16-18 June 2010

[5] Sukin Park; Yujin Song; , "An interleaved half-bridge bidirectional dcdc converter for energy storage system applications," Power Electronics and ECCE Asia (ICPE \& ECCE), 2011 IEEE 8th International Conference on , vol., no., pp.2029-2034, May 30 2011-June 32011

[6] Hua Bai; Mi, C.; , "The impact of bidirectional DC-DC converter on the inverter operation and battery current in hybrid electric vehicles," Power Electronics and ECCE Asia (ICPE \& ECCE), 2011 IEEE 8th International Conference on , vol., no., pp.1013-1015, May 30 2011June 32011

[7] Ci-Ming Hong; Lung-Sheng Yang; Tsorng-Juu Liang; Jiann-Fuh Chen; , "Novel bidirectional DC-DC converter with high step-up/down voltage gain," Energy Conversion Congress and Exposition, 2009. ECCE 2009. IEEE , vol., no., pp.60-66, 20-24 Sept. 2009

[8] Xin Guo; Xuhui Wen; Qiao, E.; , "A DSP Based Controller for High Power Dual-Phase DC-DC Converters," Power Electronics and Motion Control Conference, 2006. IPEMC 2006. CES/IEEE 5th International, vol.1, no., pp.1-5, 14-16 Aug. 2006.

[9] Haiping Xu; Qiao, E.; Xin Guo; Xuhui Wen; Li Kong; , "Analysis and Design of High Power Interleaved Boost Converters for Fuel Cell Distributed Generation System," Power Electronics Specialists Conference, 2005. PESC '05. IEEE 36th , vol., no., pp.140-145, 16-16 June 2005.

[10] Wujong Lee; Byung-Moon Han; Hanju Cha; , "Battery ripple current reduction in a three-phase interleaved dc-dc converter for $5 \mathrm{~kW}$ battery charger," Energy Conversion Congress and Exposition (ECCE), 2011 IEEE , vol., no., pp.3535-3540, 17-22 Sept. 2011.

[11] Dusan Graovac, Marco Pürschel, Andreas Kiep, “ MOSET Power Losses Calculation Using the Datasheet Parameters", http://www.btipnow.com/library/white_papers/MOSFET\%20Power\%20 Losses\%20Calculation\%20Using\%20the\%20DataSheet\%20Parameters.pdf.

[12] CMF10120D. Datashet www.cree.com/products/pdf/CMF10120D.pdf.

[13] IPW65R110CFD. Datasheet http://www.infineon.com/dgdl/DS_IPX65R110CFD_2_61.pdf?folderId $=\mathrm{db} 3 \mathrm{a} 3043156 \mathrm{fd} 5730115 \mathrm{c} 736 \mathrm{bcc} 70 \mathrm{ff} 2 \&$ fileId $=\mathrm{db} 3 \mathrm{a} 304330046413013$ 06abd8e2041b1.

[14] IPW60r099CP. Datasheet http://www.infineon.com/cms/en/product/PSLPopup.html?productType $=$ ff80808112ab681d0112ab6d0a2b0b74
[15] SCS120AG. Datasheet http://www.rohm.com/news/pdf/rohm_sic_diodes_cna110004_sg.pdf.

[16] AN-CoolMOS-CP-01 http://www.infineon.com/dgdl/Aplication+Note+CoolMOS+CP+\%28+ AN_CoolMOS_CP_01_Rev.+1.2\%29.pdf?folderId=db3a304412b40795 $0112 \mathrm{~b} 408 \mathrm{e} 8 \mathrm{c} 90004 \&$ fileId=db3a304412b407950112b40ac9a40688. 